\title{
Patient Care in the Intensive Care Unit?
}

\section{Diane Yorke*}

School of Nursing, University of North Carolina, Chapel Hill, USA

A stay in the intensive care unit (ICU), no matter how long or short, is often psychologically harmful leaving patients trying to remember what happened, feeling separated and disconnected, attempting to understand and make sense of the experience and remaining fearful and anxious [1].

A few years back my brother suffered encephalitis. When he recovered he spoke of losing time and not understanding what was happening to him or what had happened to him. I was most intrigued by his story of how someone, he's not sure if it was a doctor, nurse or someone else, kept yelling at him to be still and while he was trying to be but wasn't, they "put a ball and chain down my throat to restrain me." He had to be intubated for ground transport to a different hospital. No doubt, my brother was suffering delirium but one has to wonder why he could remember being intubated at all.

Quite unfortunately, my brother spent the first months of this year in and out of hospital in and out of intensive care. He started with a simple bypass, if a bypass can ever be simple, that turned into 4 subsequent surgeries for dehiscence, sternal disintegration, infection/ sepsis and wound grafting. He really appreciates that he's alive but he still gets pale if you mention intensive care. He admits to "losing it" and not being able to be still or sleep when he got out of the ICU to the step down unit. He has vivid memories of very disturbing dreams while in the ICU that he continues to try to understand the cause and meaning of.

If my brother and others who've received intensive care have such disturbing memories afterwards [2], just what is so intensive about care in the intensive care unit? If you're an intensive care health worker I'm sure you're thinking that I must never have been. You might even be surprised when I tell you I worked more than 25 years in pediatric and neonatal intensive care units. I know the work is intense. That is, I know working in an intensive care unit can be all of what intense means: powerful, forceful, concentrated, deep, extreme, severe, and passionate. The ICU is a busy environment focused on maintaining vital signs and preserving organ function. But, patients' stories of what they remember of their experience suggests to me that this extreme focus on bodily functioning in the intensive care unit is not necessarily providing all of the care that patients need.

I'm not the first to think of this. Alonso-Ovies and Calle described their distress at hearing a celebrity on television describing the intensive care unit as "a branch of hell" [3]. After wondering what could cause an ICU survivor to say such they explored the intensive care experience from the patients' point of view. What they realized is the ICU experience is filled with causes of suffering. Being excellent clinicians they made recommendations for managing this suffering. Their recommendations all center on bringing care of patients as persons to the forefront and stress the management of patient suffering.

I am quite impressed by their list. It is comprehensive. However, my brother's stories suggest there are some other even simpler ways to manage, perhaps even prevent, patients suffering in the ICU and afterwards. First, let's avoid scheduling medications through the night. My brother's night nurses told me he slept through the 2 AM antibiotic dose but my brother says he didn't; that he had to move his arm for the
IV port to be accessed. He didn't always open his eyes or speak but he was awake. The lack of sleep only added to his delirium.

Second, let us all pledge to thoroughly investigate patients', or their families', complaints of something being 'not right.' My brother required several changes of the type of bed he was in. One bed turned out to not have all of the pneumatic tubing correctly in place so part of the bed wasn't inflated for several days and nights and though he complained every day that there was something not right about his bed it wasn't until after he was able finally to get out of bed that his caregivers and nurses noticed the bed's malfunction.

Alonso-Ovies and Calle [3] list thirst as one of the causes of ICU suffering. During the times he required endotracheal intubation my brother reported that the worst thing was how dry his mouth was. He said he was so thirsty but his thirst wouldn't have been so bad if his mouth wasn't so dry. So, third, let's do mouth care much more frequently than recommended; at the very least let's do mouth care as frequently as recommended.

Fourth, let's talk to the patients in intensive care. We can tell them who we are, what we're planning to do, what we're doing and why. Not knowing why people were doing the things they were doing to him caused my brother to resist. And when he wasn't able to resist he incorporated their interventions into his delirium.

Finally, when patients get moved out of intensive care let's listen to them. Let's ask for their stories and try to reconcile what they remember. Let's help them reconnect to the world outside of and away from the ICU. We can offer truthful explanation of what happened and why. Let's provide intensive patient care.

\section{References}

1. Rattray J, Johnston M, Wildsmith J. (2004) The intensive care experience: Development of the ICE questionnaire. J Adv Nurs 47:64-73.

2. Crisp DH (2017) Anatomy of medical errors: the patient in room 2: A nurses story of surviving preventable medical errors and discovering the truth. Sigma Theta Tau International.

3. Alonso-Ovies, Calle GH (2016) ICU: A branch of hell? Intensive Care Med 42:591-592.

*Corresponding author: Diane Yorke, School of Nursing, University of North Carolina, Chapel Hill, USA, E-mail: dyorke@email.unc.edu

Received August 17, 2016; Accepted August 17, 2017; Published August 24 2017

Citation: Yorke D (2017) Patient Care in the Intensive Care Unit? J Pat Care 3: e104. doi: 10.4172/2573-4598.1000e104

Copyright: (c) 2017 Yorke D. This is an open-access article distributed under the terms of the Creative Commons Attribution License, which permits unrestricted use, distribution, and reproduction in any medium, provided the original author and source are credited. 